\title{
A Performance-Based Integrated System for the Assessment of Project Procurement Departments of Construction Companies
}

\author{
Mustafa Altındag \\ Civil Engineer, M.Sc. \\ Istanbul Technical University, Institute of Science and Technology, \\ Project and Construction Management PhD Program, Istanbul
}

\author{
Alaattin Kanoglu \\ Ph.D., Professor \\ Istanbul Technical University, \\ Faculty of Architecture, Istanbul
}

\begin{abstract}
Numerous hypotheses in the literature claim that there must be some correlations among the attributes of different types of entities such as project, organization, decision makers, etc., and performance of other entities such as sectors, companies, projects, operations, individuals etc. Project procurement departments of construction companies seem to be one of the most important entities to be investigated for this matter since their performance is vital for the companies' survival. This study is currently being conducted as one of the sub-projects of the master project entitled "SIMURG: A performance-based and Sustainability-oriented Integration Model Using Relational database architecture to increase Global competitiveness of Turkish construction industry in industry 4.0 era. The master project was designed to include research and development of related models at all hierarchical levels of performancebased design and construction of built environment approach with open-ended approach in various sub-projects in three complementary areas, i.e., product, process and social dimensions. The hierarchical levels of first two dimensions are a. building components, b. building elements, $c$. building premises, $d$. buildings, e. projects, f. lands, g. quarters, $h$. settlements, $i$. counties and $j$. cities levels on product side and $a$. operations, b. projects, c. departments, d. firms, e. groups of firms, f. sectors, g. national economies, and $h$. global economy levels on process side. Entities/facts at social dimension do not have a hierarchical structure. Each levels need their own levelspecific Key Performance Indicators (KPIs) and associated weights to be determined in addition to organisational, computational and computer models to be designed. In this study the conceptual and practical models of performance-based assessment system at departments level have been developed to solve above stated problem in "project procurement" context. The conceptual model developed in this PhD thesis for performance-based evaluation of the related department will be converted into a relational database model in the master project and will be enriched by additional functions and reports to be able to investigate the relationships among the entities of built environment, professional environment and social environment dimensions.
\end{abstract}

Keywords: SIMURG, Performance-based building, project procurement departments, competitiveness, process performance.

\section{INTRODUCTION}

Numerous hypotheses in the literature claim that there must be some correlations among the attributes of different types of entities such as project, organization, decision makers, etc., and performance of other entities such as sectors, companies, projects, operations, individuals etc. Project procurement departments of construction companies seem to be one of the most 
important entities to be investigated for this matter since their performance is vital for the companies' survival.

\section{PROBLEM STATEMENT}

Traditional assesment of project procurement processes and departments is not based on "performance" of these entities but based on "success" of the procurement process and the department. If the company is granted with the project after the project procurement process the department is assumed to be succesful. This approach is not acceptable because it does not help to explain the failure of performance of project procurement department. Thus it will not be possible to explain why the same failures are repeated and why the company can not make profit even though it is succesfull in tenders and achieves to be the winner after the procurement processes.

This is not a sustainable approach for obtaining new projects which is vital for the survival of company. That is why project procurement departments of construction copmanies need some practical models that utilize the data of past projects related to risk and advantage factors and the success and failures of related departments in estimating these factors and ther effects on bid price. Yet, comprehensive models providing this sort of analyses can not still be located in the literature.

\section{THE AIM AND OBJECTIVES OF THE STUDY}

It is the main goal of this study to develop the conceptual part of a performance-based model for the assesment of project procurement processes of construction companies and the related organisational units, i.e., departments undertaking the responsibility of this process. The objectives of the study is given below:

- Conducting a survey in Turkish construction industry for the validation of problem,

- Analysis of risk management process at procurement process,

- Investigation of performance-based approach and tools for the assesment of construction firms,

- Determination of related Key Performance Indicators (KPIs) needed for performancebased assesment of Project procurement departments of construction firms,

- Developing the conceptual model of a performance-based assessment system for the Project procurement departments of construction firms,

- Conducting a survey in Turkish construction industry for the validation of model proposed.

After developing the conceptual model at the second step the relational database software model SIMURG_PERISCOPE (A Performance-based Integrated System for Construction Companies' Procurement Departments Based on the Variations of Estimated and Actual Risks) at practical dimension will be developed in the master project entitled SIMURG_INTEGRATED [1].

\section{INTEGRATED ASSESSMENT OF PERFORMANCE OF THE ENTITIES/FACTS}

Illustration of Solar System Simulation at process dimension is given in Figure 1, which is presented by Kanoğlu et al. [1]. It explains the expansion levels of built environment entities. Just like the planets in solar system all entities at certain levels has their own spherical sizes that represent the impact factor or weight of the entity on the chosen level's entity.

The chosen entity, for example, can be at "companies" level at process dimension, if governmental departments need the calculation of performance of companies in national construction industry that are supposed to be supported; or it may be at "departments" level if 
construction companies need this calculation for monitoring the performance of their departments and preparing corrective policies for these departments which are consistent with companies' strategical priorities.

As it can be seen in the illustration there is an additional relationship between "Level_02_Companies" level in Process Dimension and "Level_03_Units" level in Product Dimension. Because the performance of built environment can't be calculated without considering the effect of performances of companies that take place in production process on the performance of built environment [2], [3], [4].

The master project was designed to include research and development of related models at all hierarchical levels of performance-based design and construction of built environment approach in two complementary areas, i.e., product and process dimensions. The hierarchical levels of product dimensions can be defined as 00_building components, 01_building elements, 02_building premises, 03_building units, 04_buildings, 05_projects, 06_lands, 07_quarters, 08_settlements, 09_counties and 10_cities levels as it is seen in Figure 1.

Right side of the simulation model can be extended down to subatomic levels while left side is possible to extend up to universe theoretically. Yet, for practical reasons we start with 00_components level and end with 10_cities level. As for the hierarchical levels of process dimension, the entities and their levels can be defined as 00_projects, 01_departments, 02_companies, 03_groups of companies, 04_sectors and 05_national economies, 06_global economy levels. Each level needs its own level \& type-specific KPI's and associated impact factors/weights to be determined.

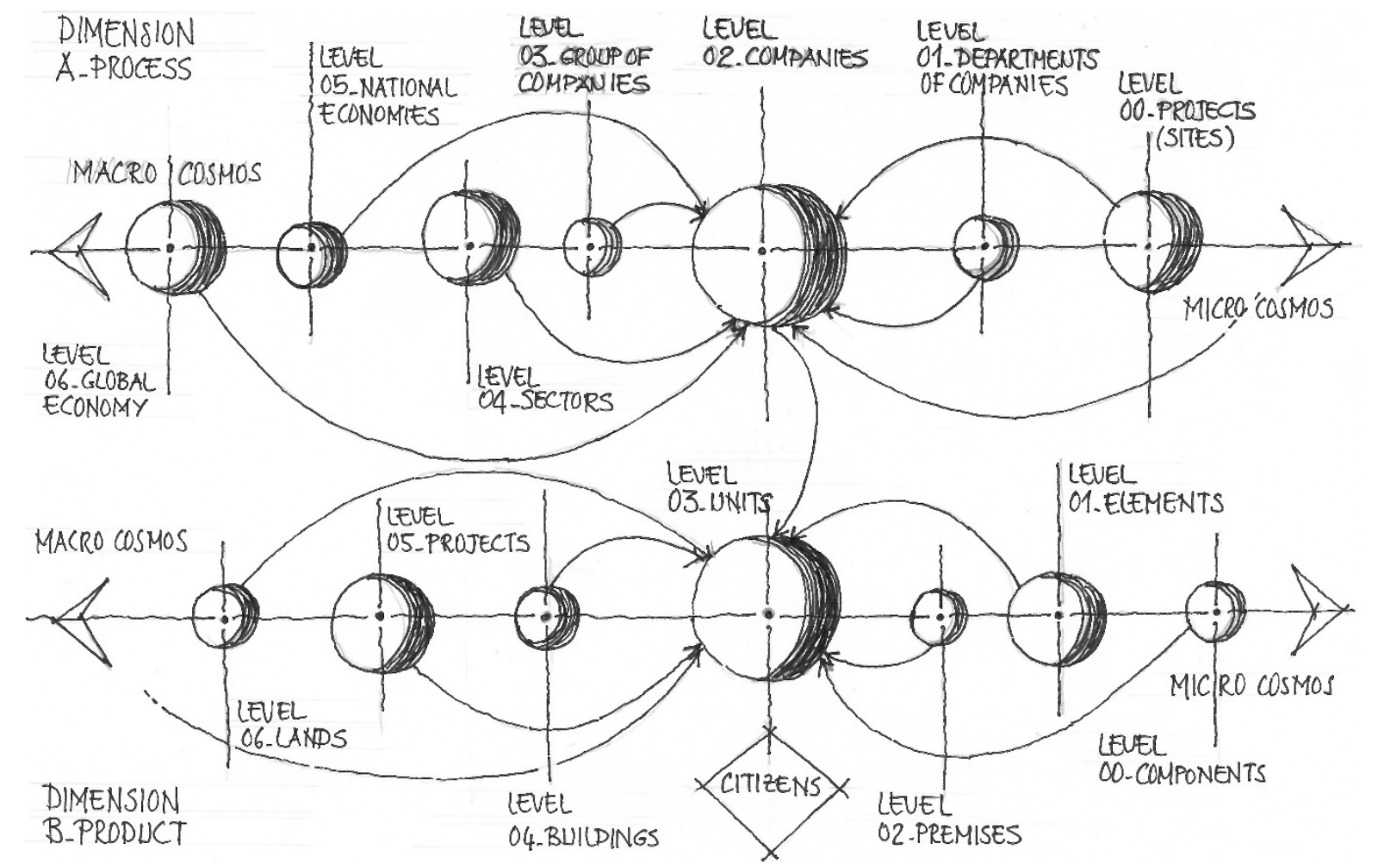

Figure 1. Solar System Simulation, which is the backbone of the model [1]

After determining the built environment's level to be analyzed, the concept/layer i.e., green, smart, slow, safe, etc., that matches with expectations of individuals or institutions in terms of the identity/character of built environment desired is decided for further analyses. Each concept/layer has its own set of KPIs including associated impact factors/weights. 
The scores are given by an expert and the individual/institution simultaneously and separately. Since the citizens are bound to the system at building unit level by the occupation information recorded in a public database maintained by the government, all the secondary level information such as educational, social, cultural, economic data related to the citizens recorded by other governmental offices can be accessed and linked/combined at desired levels of built entity by the model.

The studies handling key components of the problem and its solution at different dimensions, i.e., product and process dimensions for different entities at various levels of built environment from building components to cities levels, are being conducted by Kanoğlu et al. [1] as the subprojects of the master project entitled as "SIMURG: A performance-based and Sustainabilityoriented Integration Model Using Relational database architecture to increase Global competitiveness of Turkish construction industry in industry 4.0 era" while some of these projects are the subjects of dissertations and master theses, some of them are being studied in research and development projects funded by İTÜ BAP and private companies in construction industry.

The final product of master project is SIMURG_INTEGRATED, a relational database software, which is an open-ended model that allows numerous modules in both product and process dimensions and all levels of built environment entities in both dimensions. The whole list of projects including those scheduled but not started yet and completed or currently going on, are listed below.

SIMURG_PERISCOPE is the output of the study in Departments Level of the integrated model at Process Dimension stated above. Companies undertaking various functions such as supplier, constructor, manufacturer, etc., in production of built environment have various departments and calculation of total performance of these companies needs the same models to be developed as well. Another study in Departments Level at Process dimension is reported by Erdoğan and Kanoglu in another paper [5]. That's why this is an open-ended model that needs the further studies related to these departments to be integrated. The details of the subprojects of the master project are explained below.

\section{Subprojects of SIMURG Master Project at Product Dimension}

SIMURG Master Project includes 7 subprojects at starting point that are matching with some levels of built environment entities at product dimension as it is explained in Solar System Simulation in Figure 1. Two of these subprojects are currently being studied by $\mathrm{PhD}$ students in their dissertations; SIMURG_PROJECTS and SIMURG_CITIES.

- SIMURG_CITIES: The study is currently being conducted by Ulker under the supervision of Kanoglu and Özçevik [6] in her dissertation entitled SIMURG_CITIES: A PerformanceBased Integrated Model for Design and Evaluation of Sustainable and Sophisticated Solutions at Cities Level: Determination of Key Performance Indicators and Principles of Model at Conceptual Dimension. Main goal of the project is to determine the key performance indicators (KPIs) of performance of built environments at Cities Level in terms of the combinations of level-specific and layer (concept)-specific KPIs in both Expert and User point of views and integrate the findings with SIMURG_INTEGRATED, final output of the master project.

- SIMURG_PROJECTS: The study is conducted by Varlier under the supervision of Ozcevik and Kanoglu [7] in her dissertation entitled SIMURG_PROJECTS: A Performance-Based Integrated Model for Design and Evaluation of Sustainable and Sophisticated Solutions at Projects/Gated Communities Level: Search for the Lean Architecture of Relational Database. Main goal of the project is to determine the key performance indicators 
(KPIs) of performance of built environments at Projects/Gated Communities Level in terms of the combinations of level-specific and layer-specific KPIs in both Expert and User point of views and integrate the findings with SIMURG_INTEGRATED, final output of the master project.

\section{Subprojects of SIMURG Master Project at Process Dimension}

SIMURG, the master project, includes 6 subprojects at starting point that are matching with the related levels of built environment entities at process dimension as it is explained in Solar System Simulation in Figure 1. Two of these projects, SIMURG_IDEPRO and SIMURG_ MORPHO_BLUE were completed and four subprojects are currently being studied by graduate students in their master theses; SIMURG_PERISCOPE, SIMURG_ARCADIA, SIMURG_HELMET and SIMURG_CITIES.

- SIMURG_IDEPRO: The study was conducted by Arslan, under the supervision of Kanoglu [2], [3], [4] in his dissertation entitled SIMURG_IDEPRO: Integration of Design and Procurement Processes of Construction Projects. Main goal of the project is to develop the conceptual model of integration of design and project procurement processes in construction projects.

- SIMURG_MORPHO_BLUE: The project conducted by Yazicioglu and Kanoglu [8] was funded by İTÜ BAP and Dogtas - Kelebek Mobilya, the companies producing and marketing furniture and kitchen systems. The details of the research project were published recently in 7 consecutive articles by Yazicioglu and Kanoglu [8], [9], [10], [11], [12], [13], [14]. This project deals with determination of KPIs of kitchen design process and provides a practical tool for this sort of companies in both departments and projects levels, to be able to assess the performance of their associated design offices.

- SIMURG_PERISCOPE: The study is currently being conducted by Altindag, under the supervision of Kanoglu in his dissertation entitled SIMURG_PERISCOPE: A Performancebased Integrated System for Construction Companies' Procurement Departments Based on the Variations of Estimated and Actual Risks. Main goal of the project is to develop a conceptual model of calculation of the performance of project procurement departments of construction companies.

- SIMURG_HELMET: The study is currently being conducted by Erdogan, under the supervision of Kanoglu [5] in his master thesis entitled SIMURG_HELMET: An Integrated Solution for the Departments of Health of Labourers and Safety of Work in Construction Firms and a Relational Database Model for the Evaluation and Tracking the Performance of Department. Main goal of the project is to develop a conceptual model of calculation of the performance of health and safety departments of construction companies using past and current projects records of accidental events.

- SIMURG_ARCADIA: The study is currently being conducted by Akturk, under the supervision of Kanoglu [15] in her master thesis entitled SIMURG_ARCADIA: $A$ Performance-based Relational Database Model to Increase Competitiveness/ Transparency/Accountability and Sustainability of Architectural Design Competitions in Professional Practice and Academia. Main goal of the project is to develop a conceptual model of calculation of the performance of design offices in architectural design competitions and student projects in academia using NAAB student performance criteria as KPIs.

\section{SIMURG_PERISCOPE: A PERFORMANCE-BASED ASSESSMENT MODEL FOR PROJECT PROCUREMENT DEPARTMENTS OF CONSTRUCTION FIRMS}

Integrated assessment of built environment needs to consider the performance-based assessment at three dimensional system;

- Built-environment dimension, which includes hierarchical levels of expansion 
- Professional environment dimension, which includes hierarchical levels of expansion

- Social environment dimension, which includes non-hierarchical entities/facts

Total performance of built environment can only be analysed by considering the effects of performances of entities/facts at the other two dimensions on built environment. This study deals with the entities Departments/Branches level of Professional Environment dimension. Different KPI sets according to various concepts such as safe, slow, smart, resilient, etc., can be used in the assessment of performances of the entities/facts at this three dimensional system.

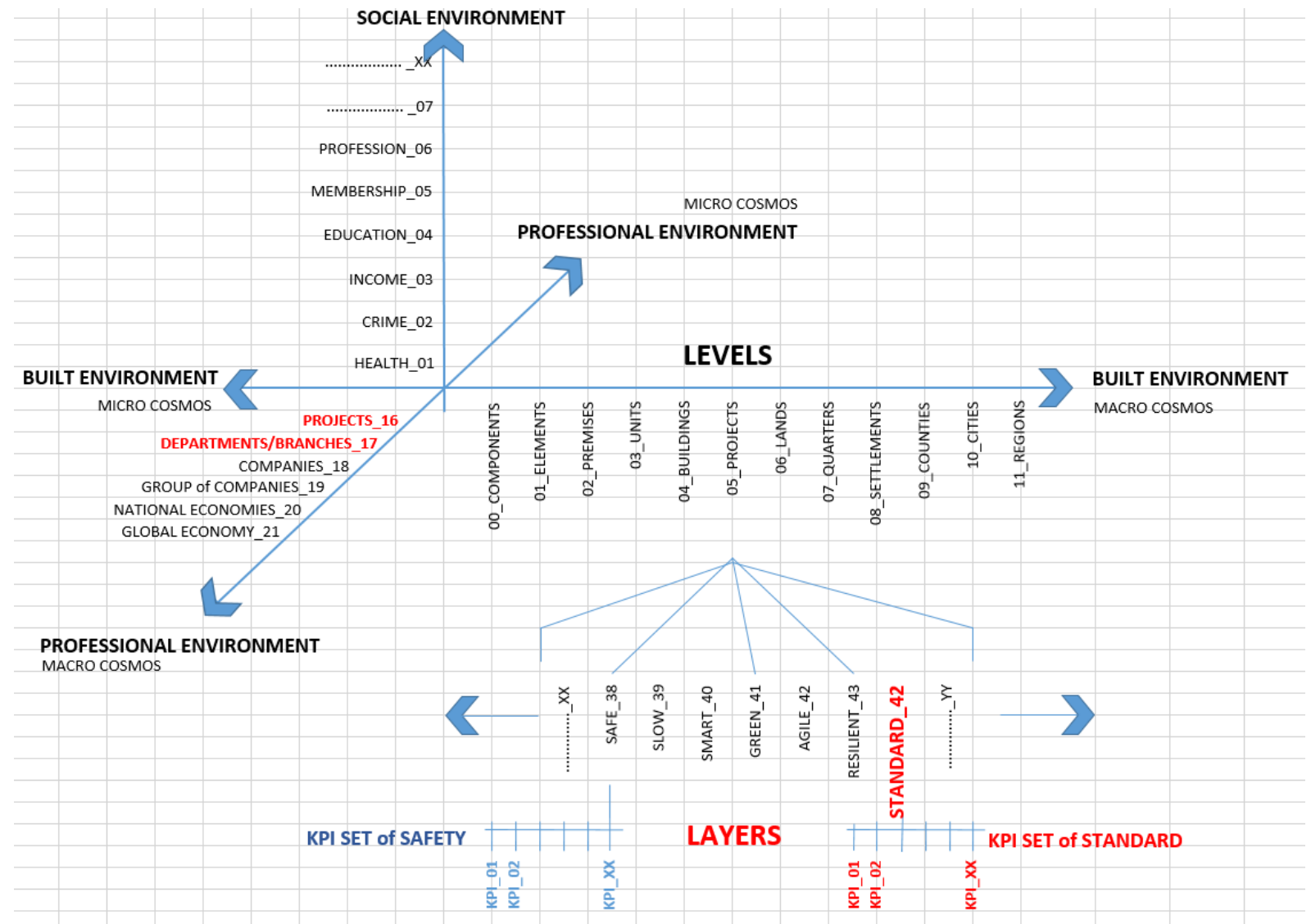

Figure 2. Location of the study on three dimensional system

The efforts for the solution of problem must provide the models at 6 interrelated dimension (Figure 3);

1. Conceptual Model: Identification of principals of solution, which will guide the researchers to develop following models.

2. Philosophical/Paradigmatic Model: Proposal of a new approach, understanding and mode of production to the construction sector of the study and the model to be produced is the main target within this context.

3. Process-Related/Organizational Model: The definition of organizational entities, relations, rights, authorities and responsibilities, which will be covered through the study and the model to be produced is the main target within this context.

4. Integration/Interoperability Model: Identification of integration processes between various stages of production is the main target within this context.

5. Computational/Evaluation Model: Determination of design and production performance parameters and performance criteria and development of a performancebased evaluation system for the built environment is the main target within this context. 
6. Computer/Software Model: Identification of processes, modules and components for automation software and reporting system is the main target within this context.

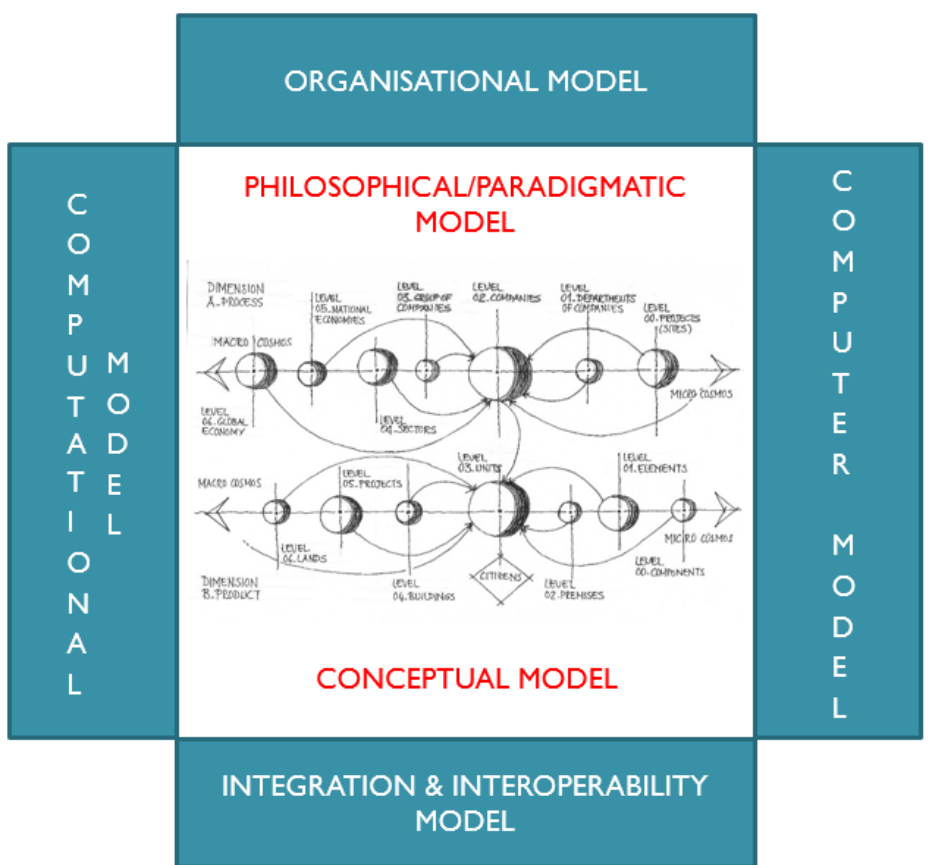

Figure 3. Components of proposed solution

\section{Conceptual Model}

In traditional approach the evaluation process is based on "success", not on "performance". It is assumed that the company and its procurement department is succesfull if the project is granted to the company. Experiences in the past projects are recorded in an unstructured format, mostly in spreadsheet files and interoperability does not exist; the data can not be combined and used in an integrated way. It is not mostly possible to be able to make analytical assessments using the data of past bidding processes.

Whereas the conceptual model must take into consideration all risk and advantage factors and estimated values of their effects on bid price must be determined and recorded. The actual and estimated values must be recorded by the end of production process and close out phase and finally the absolute variances between actual and estimated values of the effects of advantage and risk values on bid price must be calculated. These variances can be converted to performance scores on the basis of KPIs (risk and advantage factors) thus the performance of project procurement department can be determined. Performance of the project procurement department can not be determined before the project is fully completed; since the determination of performance must be based on these variances stated above in the proposed conceptual model (Figure 4). 


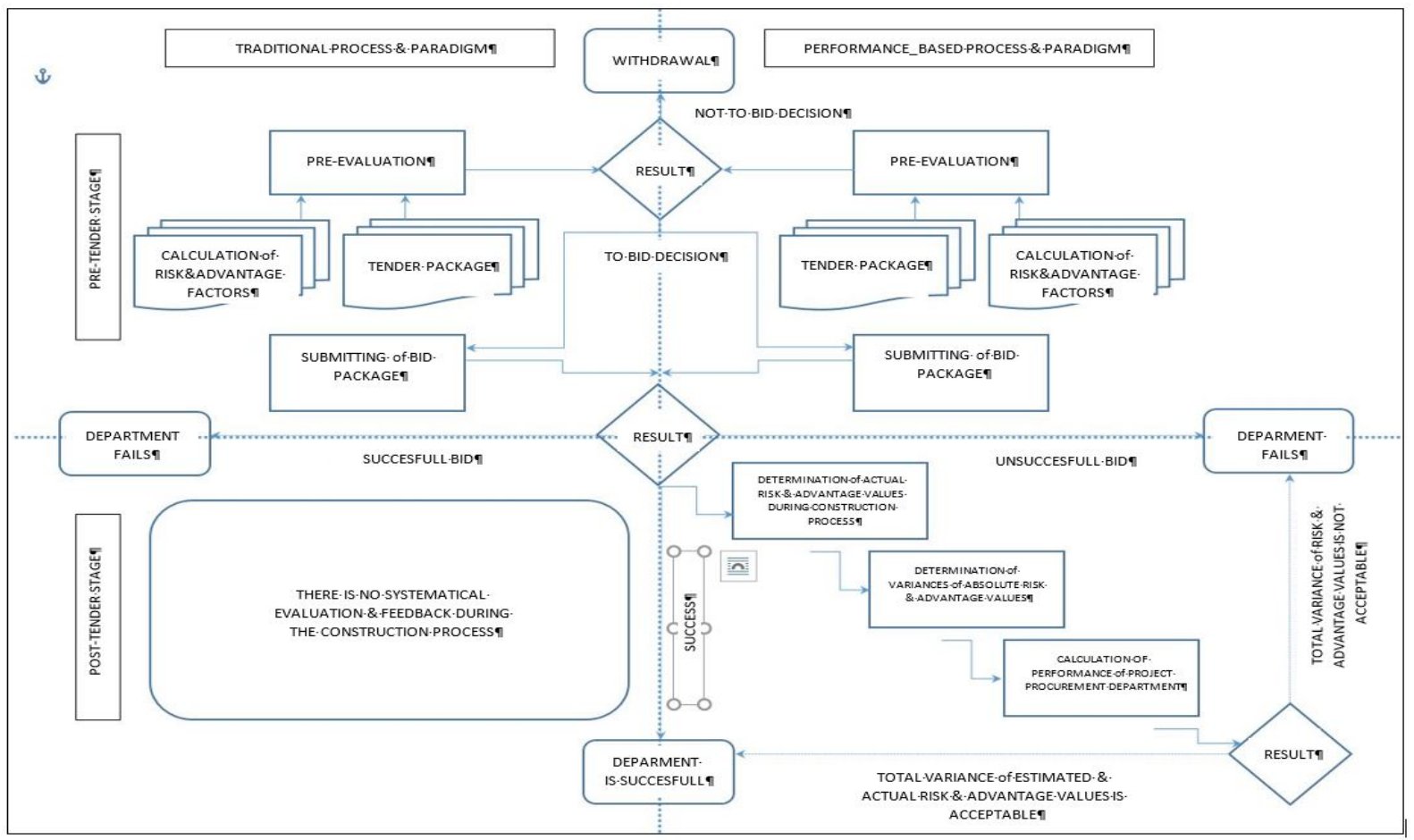

Figure 4. Conceptual model

\section{Organisational Model}

The model proposes a certificate-based assessment of the firms and the other entities at all levels of three dimensional system given above, which assumes the governmental institutions to be re-organized. That's why it needs accredited expert institutions, which will serve at all levels of expansions of built environment and other dimensions. Moreover, information creted by these certification institutions, which test/inspect the entities/facts must be made accessible by a central/governmental institution or distributed models must be developed for gathering, recording and distributing the performance information of the entities/facts.

\section{Computational Model}

Computational model proposes the calculation of the performances of each entities/facts seperately first using preferred KPI set. Then the weights of effects of each entity on the selected entity, which will be the subject of final calculation is considered in the calculation of total performance of selected entity.

\section{Practical Model}

The relational database architecture that is based on this conceptual model is currently being developed in the master project SIMURG_INTEGRATED. The software model at practical dimension use MS Access platform. The model first records the values of risk and advantage factors estiamated by first and second teams, which are assigned to prepare two simultaneous bids for the same project. One of the teams is the team assigned by project procurement department and the other one is the team, which will undertake the responsibility of construction of project in case of being awarded with the contract. The database is structured to include probability values and cost and revenue effects of risk and advantage factors as well.

\section{CONCLUSIONS}

Applicability of performance-based assessment approach is considered to create a holistic effect if it can be achieved integratedly by including all levels and entities in the production process of built environment. Project procurement departments of construction companies will try to fulfill their function by applying this new approach. Construction companies will 
have to cooperate and collaborate with design offices more closely to be able to gain competitive advantage that can only be obtained by some new concepts such as competition by design and apart innovative approachs and solutions will increase in design and construction phases of building production process. Turkish construction industry will benefit the results of this approach widely. The model proposed in this study is only one of the steps that will increase the effectiveness of performance-based building approach through project procurement processes. The output of this study will contribute to the solution of the problem at Process Dimension, while the other studies aim to contribute at Product Dimension.

\section{References}

Kanoglu, A., Yazicioglu, D.A., and Ozcevik, O., (2018). "SIMURG: A Performance-Based and Sustainability-Oriented Integration Model Using Relational Database Architecture to Increase Global Competitiveness of Turkish Construction Industry in Industry 4.0 Era", $5^{\text {th }}$ International Project and Construction Management Conference, November 16-18, Girne, North Cyprus, pp.190-199.

Arslan, S., and Kanoglu, A., (2010). "Başarım Tabanlı Yapım: Anahtar Kavramlar, Olanaklar, Bariyerler ve Bir Model, 1. Proje ve Yapım Yönetimi Kongresi, ODTÜ, 29 Eylül - 01 Ekim, Ankara.

Arslan, S., and Kanoglu, A., (2018). "Performance-Based Building: Key Concepts, Opportunities, Barriers and Paradigm of Proposed Solution", Advances in Social Sciences Research Journal, 5(3), pp. 407-417.

Arslan, S., and Kanoglu, A., (2018). "Performance-Based Building: Architecture of an Integrated Model at Conceptual and Practical Dimensions", Advances in Social Sciences Research Journal, 5(3), pp. 418-432.

Erdoğan, B., and Kanoğlu, A., (2018). "SIMURG_HELMET: An Integrated Solution for the Departments of Health of Labourers and Safety of Work in Construction Firms and a Relational Database Model for the Evaluation and Tracking the Performance of Department", $5^{\text {th }}$ International Project and Construction Management Conference, November 16-18, Girne, North Cyprus, pp. 382-389.

Ulker, B., Kanoglu, A., and Ozcevik, O., (2018). "SIMURG_CITIES: A Performance-Based Integrated Model for Design and Evaluation of Sustainable and Sophisticated Solutions at Cities Level: Determination of Key Performance Indicators and Principles of Model at Conceptual Dimension", $5^{\text {th }}$ International Project and Construction Management Conference (IPCMC2018), November 16-18, Girne, North Cyprus, pp.282-289.

Varlıer, N., Ozcevik, O., and Kanoglu, A., (2018). "SIMURG_PROJECTS: A Performance-Based Integrated Model for Design and Evaluation of Sustainable and Sophisticated Solutions at Projects Level of Built Environment: Search for the Lean Architecture of Relational Database", $5^{\text {th }}$ International Project and Construction Management Conference, November 16-18, Girne, North Cyprus, pp.759-766.

Yazicioglu, D.A., and Kanoglu, A., (2018). "SIMURG_MORPHO_BLUE: A Performance-Based Integrated Model at Building Premises Level: Analysis of Differences in Clients' and Designers' Value Systems in Kitchen Design", $5^{\text {th }}$ International Project and Construction Management Conference (IPCMC2018), November 16-18, Girne, North Cyprus.

Yazicioglu, D.A., and Kanoglu, A., (2015). "Enhancement of the Designer Performance in Kitchen Interior Design", Advances in Social Sciences Research Journal, Vol. 2, No. 6, 1-8.

Yazicioglu, D.A., and Kanoglu, A., (2016). "Determining Effects of Kitchen Design Rules on Kitchen Functionality in A Comparative Way", Academic Research International, Vol. 7, No. 3, 25-44.

Yazicioglu, D.A., and Kanoglu, A., (2016). "A Systematic Approach for Increasing the Success of Kitchen Interior Design within the Context of Spatial User Requirements", Advances in Social Sciences Research Journal, Vol. 3, No. 1, 155-166.

Yazicioglu, D.A., and Kanoglu, A., (2016). "Improving the Project Service Performance of Companies Producing and Marketing Kitchen Systems to Provide Sectoral Competitiveness", International Journal of Sciences: Basic and Applied Research, Vol. 26, No. 2, 18-27.

Yazicioglu, D.A., and Kanoglu, A., (2016). "Performance-Based Automation System for Kitchen Interior Design", Advances in Social Sciences Research Journal, Vol.3, No.13, 27-45

Yazicioglu, D.A., and Kanoglu, A., (2017). "Improving the Project Service Performance of Companies Producing and Marketing Kitchen Systems: Stage of Survey and Analysis of the Space", International Journal of Advanced and Applied Sciences, Vol.4, No.2, 139-146. 
Altındag, M., \& Kanoglu, A. (2018). A Performance-Based Integrated System for the Assessment of Project Procurement Departments of Construction Companies. Advances in Social Sciences Research Journal, 5(12) 335-344.

Akturk, S., and Kanoglu, A., (2018). SIMURG_ARCADIA: "A Performance-Based Integrated Relational Database Model for the Assessment Processes of Architectural Design Competitions in Professional Practice and Architectural Design Studios in Academia", $5^{\text {th }}$ International Project and Construction Management Conference, November 16-18, Girne, North Cyprus, pp. 324-331. 